\title{
High-mobility group AT-hook protein 2 expression and its prognostic significance in MGMT methylated and unmethylated glioblastoma
}

\author{
FRANK P. SCHWARM ${ }^{1}$, FLORIAN UHLE ${ }^{2}$, ANNE SCHÄNZER ${ }^{3}$, TILL ACKER $^{3}$, MARCO STEIN $^{1}$, \\ MARCUS H.T. REINGES ${ }^{1}$, CORNELIA WEISCHER ${ }^{1}$, MARCUS A. WEIGAND ${ }^{2}$, \\ EBERHARD UHL ${ }^{1}$ and MALGORZATA A. KOLODZIEJ ${ }^{1}$
}

${ }^{1}$ Department of Neurosurgery, Justus-Liebig University Giessen, Giessen; ${ }^{2}$ Department of Anesthesiology,
University of Heidelberg, Heidelberg; ${ }^{3}$ Institute of Neuropathology, Justus-Liebig University Giessen, Giessen, Germany

Received October 29, 2015; Accepted December 29, 2015

DOI: 10.3892/ijo.2016.3397

\begin{abstract}
High-mobility group AT-hook protein 2 (HMGA 2) is a transcription factor associated with malignancy and poor prognosis in a variety of human cancers. We correlated HMGA 2 expression with clinical parameters, survival, and O-6-methylguanine-DNA methyltransferase methylation status (MGMT) in glioblastoma patients. HMGA 2 expression was determined by performing quantitative real-time polymerase chain reaction (qPCR) and immunohistochemistry (IHC) in 44 glioblastoma patients and 5 non-tumorous brain specimens as controls. Gene expression levels of MGMT methylated vs. unmethylated patients, and gene expression levels between patient groups, both for qPCR and IHC data were compared using the Mann-Whitney U test. The relationship between HMGA 2 expression, progression-free survival and overall survival was analyzed using the Kaplan-Meier method and the log-rank test. P-values of $<0.05$ were considered statistically significant throughout the analyses. The mean age of patients at diagnosis was $57.4 \pm 15.7$ years, and the median survival was 16 months (SE 2.8; 95\% CI, 10.6-21.4). HMGA 2 gene expression was significantly higher in glioblastoma compared
\end{abstract}

Correspondence to: Dr Malgorzata Kolodziej, Department of Neurosurgery, Justus-Liebig University Giessen, Klinikstrasse 33, I-35392 Giessen, Germany

E-mail: malgorzata.kolodziej@neuro.med.uni-giessen.de

Abbreviations: EMT, epithelial-mesenchymal-transition; GBM, glioblastoma multiforme; HMG, high-mobility group; IHC, immunohistochemistry; IRS, immunoreactive score; MGMT, O-6-methylguanine-DNA methyltransferase; mRNA, messenger RNA; OS, overall survival; PFS, progression-free survival; qPCR, real-time quantitative PCR; RCT, radiochemotherapy; RNA, ribonucleic acid

Key words: glioblastoma, high-mobility group 2, MGMT methylation, patient survival to normal brain tissue on qPCR (mean, $0.35 ; \mathrm{SD}, 0.27$ vs. 0.03 , $\mathrm{SD}, 0.05$ ) and IHC levels (IRS mean, 17.21; SD, 7.43 vs. 3.20; $\mathrm{SD}, 1.68)(\mathrm{P}=0.001)$. Survival analysis revealed that HMGA 2 overexpression was associated with a shorter progression-free and overall survival time in patients with methylation $(n=24)$. The present study shows a tendency that HMGA 2 overexpression correlates with a poor prognosis of glioblastoma patients independent of MGMT methylation status. The results suggest that HMGA 2 could play an important role in the treatment of glioblastoma and could have a function in prognosis of this type of cancer.

\section{Introduction}

High-mobility group (HMG) proteins are heterogeneous non-histone DNA-binding factors that organize active chromatin (1). High-mobility group AT-hook protein 2 (HMGA 2) belongs to this family and is located at chromosome 12q14 and encodes an 109 amino acid protein. The functional unit of all HMGA proteins are 3 copies of a conserved DNA-binding peptide motif ('AT-hooks') that cause the binding to adeninethymine (AT)-rich regions of nuclear DNA $(2,3)$. HMGA 2 is expressed primarily in the early embryonic development, and is suppressed in differentiated cells (4). Some reports suggest that HMG proteins regulate the expression of one or more genes that control embryonic cell growth and differentiation $(1,4)$. Furthermore, HMG may also affect the expression of oncogenes and tumor suppressor genes (5). HMGA 2 is regulated by let-7, a tumor suppressor microRNA (miRNA), which is downregulated in regards to cancer development (6). A directly regulatory relationship between let-7a (member of let-7 family) and HMGA 2 regulation has been confirmed in breast, lung and esophageal cancers (7-9).

HMGA 2 is not expressed in normal human adult tissue but it can be detected in many human tumors including lipoma, leiomyoma and pituitary tumors, which are benign tumors but they can be very invasive $(10,11)$. Furthermore, HMGA 2 is also expressed in malignant neoplasms such as colorectal, lung, gastric, ovarian and breast cancers, neuroblastoma and glioblastoma (12-19). 
Prior studies showed that miR-142-3p, a miRNA in pluripotent stem cells, suppresses the expression of HMGA 2 targeting the 3'UTR, and thus, decreasing the expression of Sox 2, a transcription factor in stem cells. HMGA 2 increases the transcription of Sox 2 through directly binding to the Sox 2 promoter gene region. Patients with an upregulated HMGA 2 expression demonstrated a poor overall survival (20). miRNA alterations are involved in the initiation and progression of human cancer (6). Morishita et al (21) conducted a study demonstrating the molecular mechanisms of HMGA 2 in tumor pathogenesis through activation of the TGF $\beta$ signaling pathway, a major inducer of the epithelial-mesenchymal-transition (EMT), in epithelial carcinomas. Their results showed that HMGA 2 plays a critical role in inducing tumor invasion, and metastasis in EMT by activating the TGF $\beta$ signaling pathway.

A study by Liu et al (16) presented a significant correlation of HMGA 2 expression, and glioblastoma cell proliferation, invasion and survival. Glioblastomas are highly invasive, rapidly growing, scatter along the white matter tracts and their structure is poorly differentiated. Furthermore, glioblastoma represents the most aggressive type of glial brain tumors. Treatment is rarely effective despite gross total resection, chemotherapy, radiotherapy or all of them (22). MGMT (O-6-methylguanine-DNA methyltransferase) methylation status and the analysis of IDH1 and IDH2 mutations has become diagnostic and prognostic standards, and there are numerous studies investigating new molecular markers for a better characterization of this tumor entity (23-25).

Unfortunately, the recurrence of glioblastoma is still inevitable after a median progression-free period of 6.8 months (26). Consequently, novel therapies targeting cell proliferation and invasion e.g. through gene therapy may become a more effective strategy (27).

Based on the available data, HMGA 2 could be a biomarker and a potential target in glioblastoma therapy. Therefore, in the present study, we investigated the expression of HMGA 2 in glioblastoma patients, and we correlated the expression data with clinical parameters, survival and MGMT methylation status.

\section{Materials and methods}

Patient data. A retrospective analysis of medical records was conducted and clinical data were extracted. Variables assessed include: birth date, gender, date of diagnosis, date of operation/reoperation, type/date of chemotherapy, type/date of radiotherapy, MRI follow-up reports, relapse status, date of relapse, date of last follow-up, and vital status at last followup. All patients were periodically followed for survival. The follow-up period was calculated from the date of surgery to the date of last contact. The time of progression-free survival (PFS) was defined as at the time of initial surgical therapy to tumor recurrence.

Tissue specimens. A total of 44 diagnostically confirmed cases of glioblastoma (WHO IV) were retrieved as formalinfixed, paraffin-embedded tissue blocks and kryopreserved tissue between 2006 and 2012 from the Department of Neuropathology, University of Giessen, Giessen, Germany.
Five normal brain tissue specimens were used as reference for tumor-free brain tissue and a breast cancer specimen was used as a positive control provided by the same institution. The present study was approved by the local ethics committee (application number: AZ 07/09).

RNA-isolation, quantitative real-time PCR. RNA-isolation was performed from frozen specimens stored in fluid nitrogen using the RNeasy Lipid Tissue Mini kit ${ }^{\circledR}$ from Qiagen $\mathrm{GmbH}$ (Hilden, Germany). RNA concentration was measured photometrically (peqLab NanoDrop ${ }^{\circledR} 1000$ Spectrophotometer; VWR International GmbH Life Science Competence Center, Erlangen, Germany). Total RNA ( $1 \mu \mathrm{g})$ was used for cDNA synthesis with the QuantiTect ${ }^{\circledR}$ reverse transcription kit (Qiagen). Quantitative real-time PCR (qPCR) was performed along with the following human primers with the Mastercycler Gradient Thermal Cycler ${ }^{\circledR}$ (Eppendorf, Hamburg, Germany): actin- $\beta$, human (Hs99999903), IPO8, human (Hs00914040), HMGA 2, human (Hs00171569_m1), TBP, human (Hs00427620) (all from Life Technologies Inc., Carlsbad, CA, USA). Reaction setup and cycling conditions adhered to the kit manual. Reaction efficiency was determined using standard curves, gene expression levels calculated by the $\Delta \Delta \mathrm{Ct}$ method and expressed as efficiency corrected $\log 2$ values. Additionally, the linear $n$-fold expression ratio of cases/controls was calculated by first converting the $\log 2$ values to linear and calculating the ratio of cases/controls to facilitate easy comprehension of the gene expression changes.

Raw cycle threshold $(\mathrm{Ct})$ data of qPCR experiments were processed by subtracting the mean $\mathrm{Ct}$ of all endogenous control genes (actin- $\beta$, IPO8 and TBP) from the $\mathrm{Ct}$ of the according gene of interest (HMGA 2). Taking into account the exponential nature of PCR methodology, relative expression was obtained from the resulting $\Delta \mathrm{Ct}$ value using the formula of $2^{-\Delta \mathrm{Ct}}$.

In preliminary experiments, we analyzed samples from the individual frontal, parietal, temporal, occipital and cerebellar lobes for HMGA 2 expression using qPCR. No significant differences in expression were found between these anatomical regions (data not shown). Therefore, we did not further match the control samples to the anatomical brain regions of the tumors.

Immunohistochemistry. Of all samples investigated using qPCR, a subset of 44 tumor samples and 5 non-tumorous brain tissue samples were available as paraffin-embedded tissue and used for immunohistochemistry. Samples from breast cancers were used as positive controls. Immunohistochemical staining was performed using the BenchMark XT IHC fully automated staining instrument (Ventana Medical Systems, Tucson, AZ, USA) following the manufacturer's instructions on 3- $\mu$ m paraffin sections. A polyclonal rabbit antibody against HMGA 2 (ab52039; Abcam, Cambridge, UK) was used with a final dilution of 1:25.

Quantification of immunohistochemical staining. The sections were microscopically (Leica DMLB microscope; Leica Microsystems, Wetzlar, Germany) assessed in x200 and $\mathrm{x} 400$ magnification by two investigators (C.W. and F.P.S.) 
who were blinded to patient characteristics and outcome. Immunoreactivity score (IRS) was determined using staining intensity and number of positively stained cells (nuclear expression). Staining intensity was determined on the following scale: 0 (no staining), 1 (weak staining, light yellow), 2 (moderate staining, yellowish brown), and 3 (strong staining, brown). In addition, the percentage of positive cells was semiquantitatively determined $(0-100 \%$ in $10 \%$ steps). IRS was calculated as the product of staining intensity and percentage of positive tumor cells, resulting in a value ranging from 0 to 30 . The k-statistics of the analyzed immunohistochemical stained slides revealed a kappa value of 0.534 for HMGA 2 . Differences in assessment were discussed until consensus was reached.

Calculation of HMGA 2 gene expression and statistical analysis

qPCR and calculation of gene expression. Gene expression calculations were performed using the $\Delta \Delta \mathrm{Ct}$ method in GenEx 6 (Multid Analyses AB, Göteborg, Sweden). Stable expression of housekeeping genes $\beta$-actin (ACTB), TATAbinding protein (TBP) and importin (IPO) were assessed using the NormFinder algorithm, hereby confirming suitability of all 3 genes to be used as references in our samples. Normalization of HMGA 2 was performed against these three housekeeping genes and expression levels were calculated for normal brain tissue and glioblastoma specimens. To allow direct comparison, data are shown as $2^{-\Delta \mathrm{Ct}}$ values unless otherwise indicated.

Statistical analysis. The following statistical assessments were performed using the Mann-Whitney U test: gene expression levels in MGMT methylated vs. unmethylated patients, gene expression levels between patient groups, both for qPCR and immunohistochemical data. The relationship between HMGA2 expression, regression-free survival and overall survival was analyzed using the Kaplan-Meier method and the log-rank test. Survival analysis was performed by dividing patients into low and high expression groups. Low expression was defined as normalized gene expression levels equal or below the mean expression of each respective tumor group, while all other patients within this group were classified as high expression. To analyze further the influence of HMGA 2 expression, we performed a multivariate analysis of variance (MANOVA) stratified according to age, HMGA 2 gene expression on mRNA and protein levels, MGMT methylation status, progression-free survival (PFS) and overall survival (OS). P-values of $<0.05$ were considered statistically significant throughout the analyses.

\section{Results}

Patient collective. The patient collective included 44 gross total resected glioblastoma (WHO grade IV) patients, 40 of whom were diagnosed with primary, and 4 with secondary glioblastoma. Mean age at diagnosis was $57.4 \pm 15.7$ years. The study population consisted of 31 male and 13 female patients. The patients' median survival time was 16 months (SE 2.8; 95\% CI, 10.6-21.4). Two of the patients had received chemotherapy or radiotherapy prior to first surgery.
Table I. Summary of the baseline characteristics.

\begin{tabular}{|c|c|}
\hline & $\mathrm{n}(\%)$ \\
\hline Total cases & $44(100)$ \\
\hline Age at diagnosis (years) & $57.4 \pm 15.7)$ \\
\hline \multicolumn{2}{|l|}{ Gender } \\
\hline Male & $31(70.5)$ \\
\hline Female & $13(29.5)$ \\
\hline \multicolumn{2}{|l|}{ Survival } \\
\hline \multicolumn{2}{|l|}{ Unstratified patients } \\
\hline \multicolumn{2}{|l|}{ MGMT } \\
\hline $\begin{array}{l}\text { Methylated: } 22 \text { months } \\
\text { (SE, 3.7; 95\% CI, 14.8-29.2) }\end{array}$ & 54.5 \\
\hline $\begin{array}{l}\text { Unmethylated: } 11 \text { months } \\
\text { (SE, 2.2; 95\% CI, 6.7-15.3) }\end{array}$ & 43.2 \\
\hline \multicolumn{2}{|l|}{ Tumor entity } \\
\hline Glioblastoma & $44(100)$ \\
\hline Primary & $40(90.9)$ \\
\hline Secondary & $4(9.1)$ \\
\hline \multicolumn{2}{|l|}{ Methylation } \\
\hline \multicolumn{2}{|l|}{ MGMT } \\
\hline Hypermethylated & $24(54.5)$ \\
\hline Not hypermethylated & $19(43.2)$ \\
\hline Unavailable & $1(2.3)$ \\
\hline \multicolumn{2}{|l|}{ Neoadjuvant treatment before 1 st resection } \\
\hline \multicolumn{2}{|l|}{ Chemotherapy } \\
\hline Temozolomide & $2(4.5)$ \\
\hline \multicolumn{2}{|l|}{ Radiation } \\
\hline $60 \mathrm{~Gy}$ & $3(6.8)$ \\
\hline \multicolumn{2}{|l|}{ Initial resection } \\
\hline Resection & $41(93.2)$ \\
\hline Missing data & $3(6.8)$ \\
\hline \multicolumn{2}{|l|}{ Adjuvant treatment after initial resection } \\
\hline \multicolumn{2}{|l|}{ Chemotherapy } \\
\hline Total treated in group & $37(100)$ \\
\hline Temozolomide & $37(100)$ \\
\hline \multicolumn{2}{|l|}{ Radiation } \\
\hline Total treated in group & $38(100)$ \\
\hline 60-Gy concomitant & $36(94.7)$ \\
\hline 60-Gy stereotactic & $2(5.3)$ \\
\hline \multicolumn{2}{|l|}{ 1st recurrence } \\
\hline Total affected patients & $24(54.5)$ \\
\hline
\end{tabular}

MGMT, O-6-methylguanine-DNA methyltransferase.

Further details are listed in Table I. Five normal brain tissue specimens were used as reference for tumor-free brain tissue.

HMGA 2 mRNA expression in glioblastoma and normal brain tissue. A subset of 40 glioblastoma specimens along with 5 

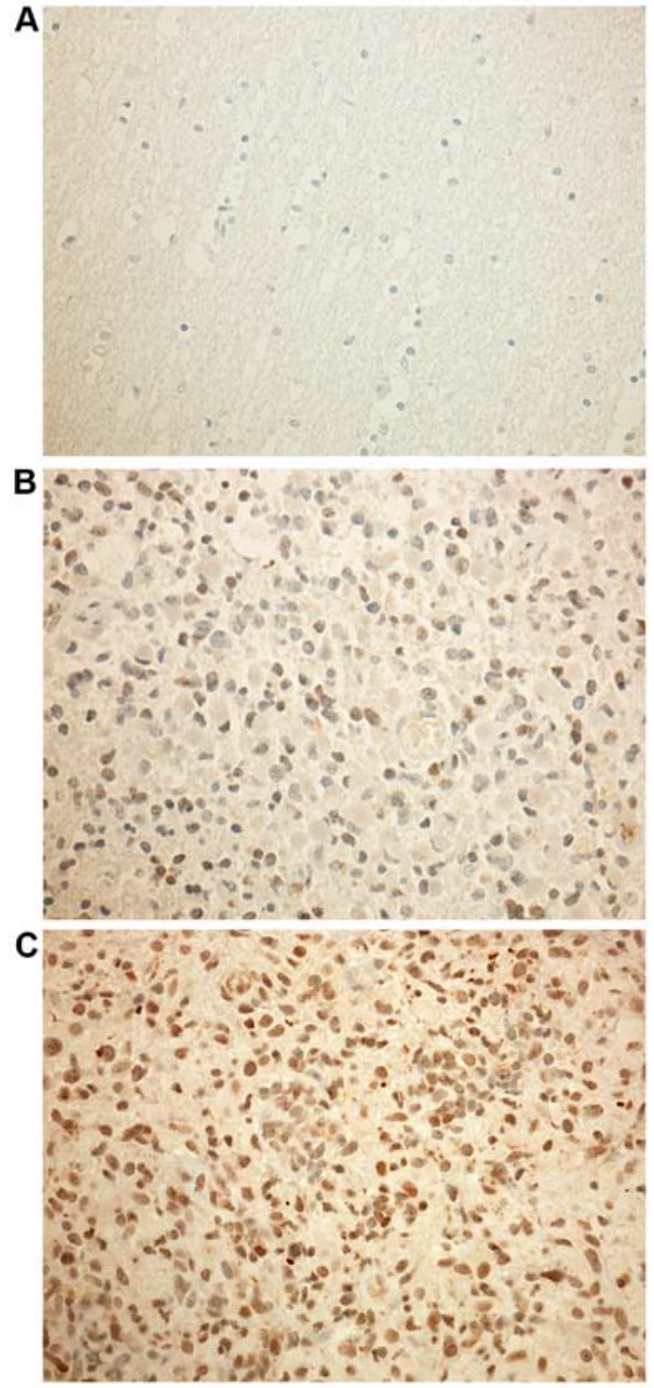

Figure 1. Representative images (magnification, $\mathrm{x} 400$ ) of HMGA 2 immunohistochemical staining show normal (A, IRS=2) and glioblastoma tissue (B and C). B (IRS=8) shows low HMGA 2 staining, C (IRS=30) an high staining in glioblastoma. The immunohistochemical staining of HMGA 2 protein is expressed higher in glioblastoma than in normal brain tissue (A vs. B and C).

\section{Expression of HMGA2 in normal brain tissue and glioblastoma}
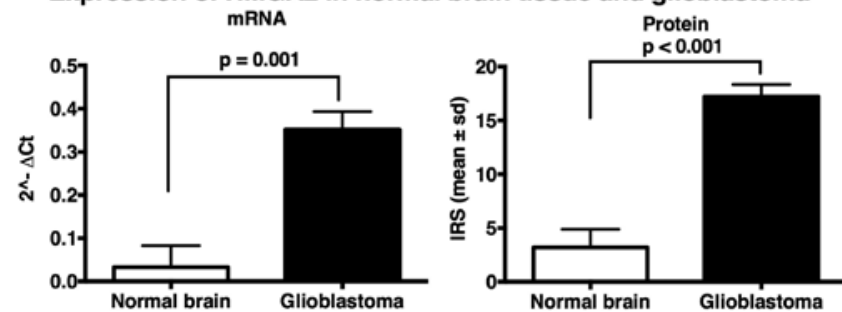

Figure 2. Expression of HMGA 2 mRNA and protein in normal brain tissue and glioblastoma with a significantly higher expression in glioblastoma.

normal brain tissues were analyzed performing qRT-PCR. The HMGA 2 expression on mRNA levels in glioblastomas were upregulated (mean, 0.35 ; SD, 0.27) compared to nontumorous brain tissue (mean, 0.03; SD, 0.05). HMGA 2 gene expression was significantly higher in glioblastoma $(\mathrm{P}=0.001)$ (Figs. 1 and 2).

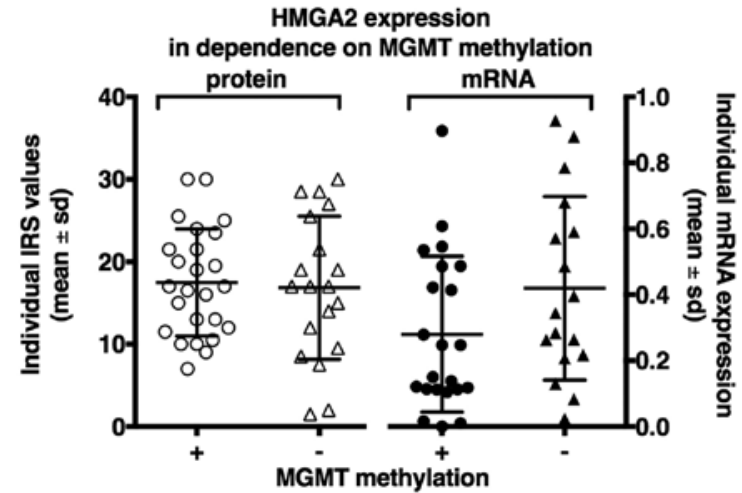

Figure 3. HMGA 2 mRNA and protein expression in all glioblastoma patients. Shown are mRNA and protein expression levels. Bars indicate mean expression and standard deviation. Marker expression was not significantly altered in MGMT methylated vs. unmethylated tumors.

HMGA 2 protein expression in glioblastoma and normal brain tissue. Forty-four glioblastoma specimens along with 5 normal brain tissues were analyzed by immunohistochemistry confirming the expression difference seen in the qRT-PCR analysis: IRS of HMGA 2 was significantly higher in glioblastoma tissue (mean, 17.21; SD, 7.43) than in normal brain tissue (mean, 3.20; SD, 1.68) $(\mathrm{P}<0.001)$. Thus, HMGA 2 gene expression was significantly higher in glioblastoma than in non-tumorous brain tissue (Figs. 1 and 2).

HMGA 2 expression as a parameter of MGMT methylation status. The analysis of HMGA 2 expression as a parameter of MGMT methylation status showed no significant differences in qPCR and immunohistochemistry analysis. On protein level there were no expression differences of HMGA 2 between methylated and unmethylated patients $(\mathrm{P}=0.87)$. On mRNA levels a slightly higher HMGA 2 expression was seen for unmethylated patients $(\mathrm{P}=0.09)$ (Fig. 3).

Progression-free survival (PFS) time as a parameter of MGMT-methylation status and HMGA 2 mRNA and protein expression. Progression-free survival (PFS) time in primary glioblastoma patients with surgical resection and adjuvant combined radio-chemotherapy with temozolomide and 60-Gy concomitant irradiation, stratified by MGMT promoter methylation was shorter with HMGA 2 upregulation (Fig. 4.) On mRNA levels 8 patients with positive MGMT promoter methylation status who had primary glioblastoma with high HMGA 2 levels had a median PFS time of 10.0 months (SE, 2.1; 95\% CI, 5.8-14.2), whereas 7 patients with primary glioblastoma and low HMGA 2 expression and methylated MGMT had a median PFS time of 21.0 months (SE, 5.2; 95\% CI 10.7-31.3) $(\mathrm{P}=0.14)$.

Three negative MGMT promoter methylation status patients with high HMGA 2 levels had a median PFS time of 8.0 months (SE, 2.4; 95\% CI, 3.2-12.8), whereas 5 patients with primary glioblastoma and low HMGA 2 expression and negative MGMT promoter methylation status had a median PFS of 5.0 months (SE, 3.3, 95\% CI 0.0-11.4) ( $\mathrm{P}=0.90)$.

Overexpression of HMGA 2 showed a tendency to a shorter PFS time. These results on mRNA level were confirmed by IRS and showed no statistical significance (Fig. 4). 

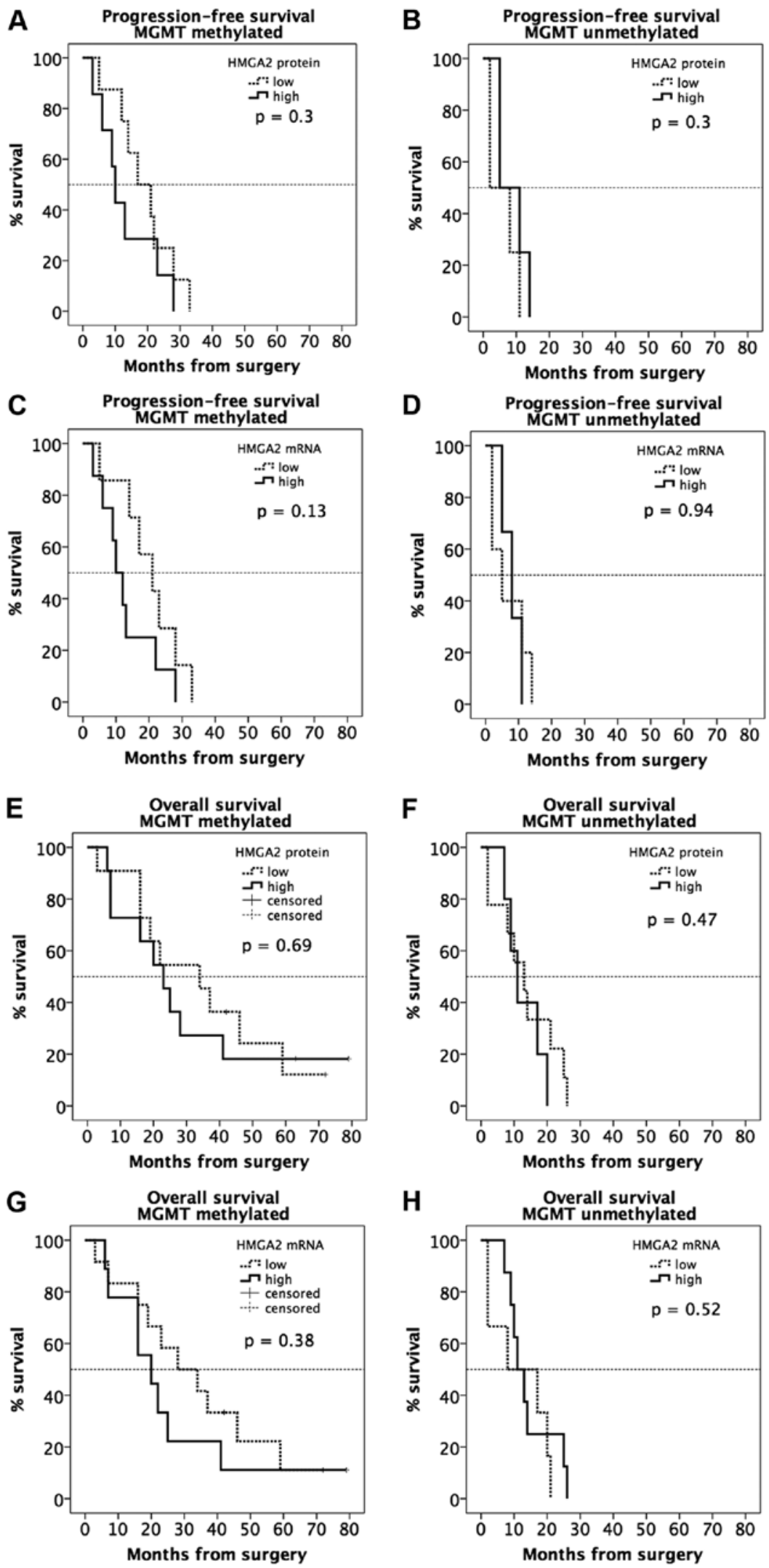

Figure 4. Progression-free and overall survival of glioblastoma patients who were resected with curative intention and received adjuvant RCT (temozolomide and 60-Gy irradiation). Patients are stratified for MGMT methylation status. Curves show progression-free time (A-D) and overall survival time (E-H) depending on HMGA 2 mRNA (C, D, G and H) and protein (A, B, E and F) expression. Overexpression of HMGA 2 shows a tendency to a shorter PFS and OS time. These results on mRNA level were confirmed by IRS and showed no statistical significance. 
and adjuvant combined radio-chemotherapy with temozolomide and 60-Gy concomitant irradiation, stratified by MGMT promoter methylation, showed a shorter OS time when HMGA 2 expression was upregulated (Fig. 4).

On mRNA levels 9 patients with positive MGMT promoter methylation status who had primary glioblastoma with high HMGA 2 levels had a median OS time of 20 months (SE, 6.0 ; 95\% CI, 8.3-31.7), whereas 12 patients with primary glioblastoma and low HMGA 2 expression and positive MGMT promoter methylation status had a median OS time of 28.0 months (SE, 9.5; 95\% CI, 9.3-46.7) ( $\mathrm{P}=0.38)$. Eight negative MGMT promoter methylation status patients with high HMGA 2 levels had a median OS of 11 months (SE, 2.1; 95\% CI, 6.8-15.2), whereas, 6 patients with primary glioblastoma and low HMGA 2 expression and negative MGMT promoter methylation status had a median OS time of 8 months (SE, 5.5; 95\% CI, 0.0-20.8) $(\mathrm{P}=0.52)$.

Overexpression of HMGA 2 was associated with a tendency to a shorter OS time. These results on mRNA level were confirmed by IRS and showed no statistical significance (Fig. 4).

Multivariate analysis. The multivariate analysis of variance (MANOVA) showed no statistical significance except for HMGA 2 expression in tumor vs. normal brain tissue $(\mathrm{P}<0.05)$.

\section{Discussion}

In the past decades advances in neuroimaging, treatment paradigms and molecular approaches enabled neurosurgeons to better understand glioblastoma and its treatment $(22,23,28$ 30). Numerous studies have been done on the invasive behavior of malignant gliomas, and there are many studies investigating new molecular markers to better characterize this tumor entity and improve clinical decision $(23,31-38)$. The current standard of care consists of microsurgical gross total resection, if possible, concurrent radiotherapy, and temozolomide chemotherapy followed by adjuvant temozolomide $(39,40)$.

Despite ongoing research efforts and aggressive treatment the median survival of glioblastoma patients still yields poor outcomes. The complete resection of the tumor is almost impossible because of the invasive growth of tumor cells and the lack of a clear border $(41,42)$. New chemotherapy approaches with temozolomide showed an improvement of survival from 12 to 14.6 months (43).

To the best of our knowledge, this is the first study analyzing on HMGA 2 expression in glioblastoma with respect to the MGMT methylation status. Our results showed that HMGA 2 overexpression has an influence on progression-free and overall survival time of glioblastoma patients.

Previous research showed that HMGA 2 is not expressed in normal brain tissue (16). Also in the present series no HMGA 2 expression was found in five normal brain tissue controls.

Furthermore, HMGA 2 is associated with poor prognosis, malignancy and invasiveness in tumors such as gastric and lung cancer, retinoblastoma and pituitary adenoma $(11,14,15,44)$. The expression of HMGA 2 correlates with the degree of malignancy of astrocytic brain tumors and shows an increase in higher grade gliomas. The highest HMGA 2 overexpression was detected in glioblastoma (16).
Inhibition of HMGA 2 leads to tumor growth inhibition and an increase of apoptosis in ovarian cancer (13). Halle et al (45) showed a possible mechanism to regulate the mRNA level of HMGA 2 due to repression of let-7a through local drug delivery with the convection-enhanced delivery (CED) technique. They showed an in vivo and in vitro de-repression of HMGA 2 after intratumoral therapy with CED. Thus, miRNAs and especially oncogenic miRNAs have the potential to impact on future cancer therapy (45).

In line with the study of Liu et al (16) in glioblastoma samples and on other human malignancies, the present study study showed that HMGA 2 was expressed in glioblastoma and not in normal brain tissue. Furthermore, overexpression of HMGA 2 in glioblastoma is reported to be closely correlated with poor survival prognosis $(16,44)$. In the present study, the overall and tumor progression-free survival time tended to be shorter in the group of patients with overexpression of HMGA 2, on IRS and qPCR levels.

Previous studies showed that MGMT promoter methylation is used to identify patients who benefit from alkylating chemotherapy. Additionally, MGMT methylation leads to a longer PFS and OS in glioblastoma patients $(40,46,47)$.

Liu et al (44) reported that aberrant HMGA 2 was associated with long-term survival of glioblastoma patients. However, in the present study patients with HMGA 2 showed a tendency to a shorter survival time (PFS and OS). Moreover, our results showed that the MGMT promoter methylation did not lead to a longer survival time in the group of patients with HMGA 2 overexpression.

Furthermore, Lee et al (48) presented in HMGA2 knocked down tumor cells a reduction of cell invasion and migration. They showed the downregulation of multiple EMT-factors such as N-cadherine (mesenchymal marker), $\beta$-catenin, transcriptional factors like Snail and Zeb 1 and upregulation of E-cadherine (epithelial marker). HMGA2 overexpression through its relationship to EMT-pathway seems to intensify invasion of cancer cells.

Morishita et al (21) showed in their in vitro experiments that HMGA 2 converts non-invasive cell types into their invasive counterparts through the induction EMT. Cells at the 'invasive front' of human tumors preferentially express HMGA 2 where the tumor cells exhibit the EMT. According to their results HMGA 2 is localized to the 'invasive front' of tumors and enables tumor cells to migrate. These findings could be a further explanation for infiltration of glioblastomas into normal brain tissue and, thus, the impossibility of a complete tumor resection and curative treatment so far. This hypothesis is speculative because it is based on other tumor entities and not glioblastomas.

As Halle et al (45) showed, the de-repression of miRNA levels of HMGA 2 through anti-let-7a application via convection-enhanced delivery (CED), HMGA 2 could be a potential target in future glioblastoma therapies with strategies for manipulating the expression of HMGA 2-regulating miRNAs.

There are several limitations of the present study. First of all there is the retrospective character of the study with the well-known shortcomings of this study design. Furthermore, the study population is small and heterogeneous, so that a selection bias cannot be excluded. 
In conclusion, the present study indicated that HMGA 2 overexpression had a tendency towards poor prognosis of glioblastoma patients independent of their MGMT methylation status. The high expression of HMGA 2 could lead to shorter survival time and poor prognosis, whereas, glioblastoma patients with low HMGA 2 expression have longer survival times (OS and PFS). HMGA 2 is an informative biomarker, which is associated with poor prognosis of patients with glioblastoma. This hypothesis may have potential implications for glioblastoma survival prediction, the choice of treatment regimens and may be helpful to create novel strategies for glioma therapy and prevention.

\section{Acknowledgements}

The authors thank sincerely Nga Rötering for excellent technical assistance, Dr Karl Quint for assistance in statistical analysis, Sabine Gräf and Boyan Garvalov for the analysis of MGMT promoter methylation.

\section{References}

1. Grosschedl R, Giese K and Pagel J: HMG domain proteins: Architectural elements in the assembly of nucleoprotein structures. Trends Genet 10: 94-100, 1994.

2. Monzen K, Ito Y, Naito AT, Kasai H, Hiroi Y, Hayashi D, Shiojima I, Yamazaki T, Miyazono K, Asashima M, et al: A crucial role of a high mobility group protein HMGA2 in cardiogenesis. Nat Cell Biol 10: 567-574, 2008.

3. Wang X, Liu X, Li AYJ, Chen L, Lai L, Lin HH, Hu S, Yao L, Peng J, Loera S, et al: Overexpression of HMGA2 promotes metastasis and impacts survival of colorectal cancers. Clin Cancer Res 17: 2570-2580, 2011.

4. Fusco A and Fedele M: Roles of HMGA proteins in cancer. Nat Rev Cancer 7: 899-910, 2007.

5. Akai T, Ueda Y, Sasagawa Y, Hamada T, Date T, Katsuda S, Iizuka $\mathrm{H}$, Okada $\mathrm{Y}$ and Chada $\mathrm{K}$ : High mobility group I-C protein in astrocytoma and glioblastoma. Pathol Res Pract 200 619-624, 2004

6. Shell S, Park SM, Radjabi AR, Schickel R, Kistner EO, Jewell DA, Feig C, Lengyel E and Peter ME: Let-7 expression defines two differentiation stages of cancer. Proc Natl Acad Sci USA 104: 11400-11405, 2007.

7. Guo L, Chen C, Shi M, Wang F, Chen X, Diao D, Hu M, Yu M, Qian L and Guo N: Stat3-coordinated Lin-28-let-7-HMGA2 and miR-200-ZEB1 circuits initiate and maintain oncostatin M-driven epithelial-mesenchymal transition. Oncogene 32: 5272-5282, 2013

8. Lee YS and Dutta A: The tumor suppressor microRNA let-7 represses the HMGA2 oncogene. Genes Dev 21: 1025-1030, 2007.

9. Liu Q, Liu T, Zheng S, Gao X, Lu M, Sheyhidin I and Lu X: HMGA 2 is down-regulated by microRNA let-7 and associated with epithelial-mesenchymal transition in oesophageal squamous cell carcinomas of Kazakhs. Histopathology 65: 408-417, 2014.

10. Fedele M, Battista S, Kenyon L, Baldassarre G, Fidanza V, KleinSzanto AJ, Parlow AF, Visone R, Pierantoni GM, Outwater E, et al: Overexpression of the HMGA2 gene in transgenic mice leads to the onset of pituitary adenomas. Oncogene 21: 3190-3198, 2002.

11. Qian ZR, Asa SL, Siomi H, Siomi MC, Yoshimoto K, Yamada S, Wang EL, Rahman MM, Inoue H, Itakura M, et al: Overexpression of HMGA2 relates to reduction of the let-7 and its relationship to clinicopathological features in pituitary adenomas. Mod Pathol 22: 431-441, 2009

12. Rizzi C, Cataldi P, Iop A, Isola M, Sgarra R, Manfioletti G and Giancotti V: The expression of the high-mobility group A2 protein in colorectal cancer and surrounding fibroblasts is linked to tumor invasiveness. Hum Pathol 44: 122-132, 2013.

13. Malek A, Bakhidze E, Noske A, Sers C, Aigner A, Schäfer $\mathrm{R}$ and Tchernitsa O: HMGA2 gene is a promising target for ovarian cancer silencing therapy. Int J Cancer 123: 348-356, 2008 .
14. Motoyama K, Inoue H, Nakamura Y, Uetake H, Sugihara K and Mori M: Clinical significance of high mobility group A2 in human gastric cancer and its relationship to let-7 microRNA family. Clin Cancer Res 14: 2334-2340, 2008.

15. Di Cello F, Hillion J, Hristov A, Wood LJ, Mukherjee M, Schuldenfrei A, Kowalski J, Bhattacharya R, Ashfaq R and Resar LM: HMGA2 participates in transformation in human lung cancer. Mol Cancer Res 6: 743-750, 2008.

16. Liu B, Pang B, Hou X, Fan H, Liang N, Zheng S, Feng B, Liu W, Guo H, Xu S, et al: Expression of high-mobility group AT-hook protein 2 and its prognostic significance in malignant gliomas. Hum Pathol 45: 1752-1758, 2014.

17. Ashar HR, Fejzo MS, Tkachenko A, Zhou X, Fletcher JA, Weremowicz S, Morton CC and Chada K: Disruption of the architectural factor HMGI-C: DNA-binding AT hook motifs fused in lipomas to distinct transcriptional regulatory domains. Cell 82: 57-65, 1995.

18. Tallini G, Vanni R, Manfioletti G, Kazmierczak B, Faa G, Pauwels P, Bullerdiek J, Giancotti V, Van Den Berghe H and Dal Cin P: HMGI-C and HMGI(Y) immunoreactivity correlates with cytogenetic abnormalities in lipomas, pulmonary chondroid hamartomas, endometrial polyps, and uterine leiomyomas and is compatible with rearrangement of the HMGI-C and HMGI(Y) genes. Lab Invest 80: 359-369, 2000.

19. Giannini G, Di Marcotullio L, Ristori E, Zani M, Crescenzi M, Scarpa S, Piaggio G, Vacca A, Peverali FA, Diana F, et al: HMGI(Y) and HMGI-C genes are expressed in neuroblastoma cell lines and tumors and affect retinoic acid responsiveness. Cancer Res 59: 2484-2492, 1999.

20. Chiou GY, Chien CS, Wang ML, Chen MT, Yang YP, Yu YL, Chien Y, Chang YC, Shen CC, Chio CC, et al: Epigenetic regulation of the miR142-3p/interleukin-6 circuit in glioblastoma. Mol Cell 52: 693-706, 2013.

21. Morishita A, Zaidi MR, Mitoro A, Sankarasharma D, Szabolcs M, Okada Y, D'Armiento J and Chada K: HMGA2 is a driver of tumor metastasis. Cancer Res 73: 4289-4299, 2013.

22. Stupp R, Hegi ME, Mason WP, van den Bent MJ, Taphoorn MJ, Janzer RC, Ludwin SK, Allgeier A, Fisher B, Belanger K, et al; European Organisation for Research and Treatment of Cancer Brain Tumour and Radiation Oncology Groups; National Cancer Institute of Canada Clinical Trials Group: Effects of radiotherapy with concomitant and adjuvant temozolomide versus radiotherapy alone on survival in glioblastoma in a randomised phase III study: 5-year analysis of the EORTCNCIC trial. Lancet Oncol 10: 459-466, 2009.

23. Weller M, Pfister SM, Wick W, Hegi ME, Reifenberger G and Stupp R: Molecular neuro-oncology in clinical practice: A new horizon. Lancet Oncol 14: e370-e379, 2013.

24. von Neubeck C, Seidlitz A, Kitzler HH, Beuthien-Baumann B and Krause M: Glioblastoma multiforme: Emerging treatments and stratification markers beyond new drugs. Br J Radiol 88: 20150354, 2015.

25. Okonogi N, Shirai K, Oike T, Murata K, Noda SE, Suzuki Y and Nakano T: Topics in chemotherapy, molecular-targeted therapy, and immunotherapy for newly-diagnosed glioblastoma multiforme. Anticancer Res 35: 1229-1235, 2015.

26. Weller M, Felsberg J, Hartmann C, Berger H, Steinbach JP, Schramm J, Westphal M, Schackert G, Simon M, Tonn JC, et al: Molecular predictors of progression-free and overall survival in patients with newly diagnosed glioblastoma: A prospective translational study of the German Glioma Network. J Clin Oncol 27: 5743-5750, 2009.

27. Kim SM, Woo JS, Jeong CH, Ryu CH, Lim JY and Jeun SS: Effective combination therapy for malignant glioma with TRAIL-secreting mesenchymal stem cells and lipoxygenase inhibitor MK886. Cancer Res 72: 4807-4817, 2012.

28. Macdonald DR, Kiebert G, Prados M, Yung A and Olson $\mathrm{J}$ : Benefit of temozolomide compared to procarbazine in treatment of glioblastoma multiforme at first relapse: Effect on neurological functioning, performance status, and health related quality of life. Cancer Invest 23: 138-144, 2005.

29. Venur VA, Peereboom DM and Ahluwalia MS: Current medical treatment of glioblastoma. Cancer Treat Res 163: 103-115, 2015.

30. Mabray MC, Barajas RF Jr and Cha S: Modern brain tumor imaging. Brain Tumor Res Treat 3: 8-23, 2015.

31. Hoelzinger DB, Mariani L, Weis J, Woyke T, Berens TJ, McDonough WS, Sloan A, Coons SW and Berens ME: Gene expression profile of glioblastoma multiforme invasive phenotype points to new therapeutic targets. Neoplasia 7: 7-16, 2005. 
32. Perego C, Vanoni C, Massari S, Raimondi A, Pola S, Cattaneo MG, Francolini M, Vicentini LM and Pietrini G: Invasive behaviour of glioblastoma cell lines is associated with altered organisation of the cadherin-catenin adhesion system. J Cell Sci 115: 3331-3340, 2002.

33. Sturm D, Witt H, Hovestadt V, Khuong-Quang DA, Jones DT, Konermann C, Pfaff E, Tönjes M, Sill M, Bender S, et al: Hotspot mutations in H3F3A and IDH1 define distinct epigenetic and biological subgroups of glioblastoma. Cancer Cell 22: 425-437, 2012.

34. Badie B and Schartner J: Role of microglia in glioma biology. Microsc Res Tech 54: 106-113, 2001.

35. Giese A, Bjerkvig R, Berens ME and Westphal M: Cost of migration: Invasion of malignant gliomas and implications for treatment. J Clin Oncol 21: 1624-1636, 2003.

36. Beije N, Kraan J, Taal W, van der Holt B, Oosterkamp HM, Walenkamp AM, Beerepoot L, Hanse M, van Linde ME, Otten A, et al: Prognostic value and kinetics of circulating endothelial cells in patients with recurrent glioblastoma randomised to bevacizumab plus lomustine, bevacizumab single agent or lomustine single agent. A report from the Dutch Neuro-Oncology Group BELOB trial. Br J Cancer 113: 226-231, 2015.

37. Deviers A, Ken S, Filleron T, Rowland B, Laruelo A, Catalaa I, Lubrano V, Celsis P, Berry I, Mogicato G, et al: Evaluation of the lactate-to-N-acetyl-aspartate ratio defined with magnetic resonance spectroscopic imaging before radiation therapy as a new predictive marker of the site of relapse in patients with glioblastoma multiforme. Int J Radiat Oncol Biol Phys 90: 385-393, 2014.

38. Hutterer M, Nowosielski M, Haybaeck J, Embacher S, Stockhammer F, Gotwald T, Holzner B, Capper D, Preusser M, Marosi C, et al: A single-arm phase II Austrian/German multicenter trial on continuous daily sunitinib in primary glioblastoma at first recurrence (SURGE 01-07). Neuro Oncol 16: 92-102, 2014.

39. Lacroix M, Abi-Said D, Fourney DR, Gokaslan ZL, Shi W, DeMonte F, Lang FF, McCutcheon IE, Hassenbusch SJ, Holland E, et al: A multivariate analysis of 416 patients with glioblastoma multiforme: Prognosis, extent of resection, and survival. J Neurosurg 95: 190-198, 2001.
40. Hegi ME, Diserens AC, Gorlia T, Hamou MF, de Tribolet $\mathrm{N}$, Weller M, Kros JM, Hainfellner JA, Mason W, Mariani L, et al: MGMT gene silencing and benefit from temozolomide in glioblastoma. N Engl J Med 352: 997-1003, 2005.

41. Nestler U, Lutz K, Pichlmeier U, Stummer W, Franz K, Reulen HJ and Bink A; 5-ALA Glioma Study Group: Anatomic features of glioblastoma and their potential impact on survival. Acta Neurochir (Wien) 157: 179-186, 2015.

42. Matsukado Y, MacCarty CS and Kernohan JW: The growth of glioblastoma multiforme (astrocytomas, grades 3 and 4) in neurosurgical practice. J Neurosurg 18: 636-644, 1961.

43. Becker KP and Yu J: Status quo - standard-of-care medical and radiation therapy for glioblastoma. Cancer J 18: 12-19, 2012.

44. Liu Y, Shete S, Etzel CJ, Scheurer M, Alexiou G, Armstrong G, Tsavachidis S, Liang FW, Gilbert M, Aldape K, et al: Polymorphisms of LIG4, BTBD2, HMGA2, and RTEL1 genes involved in the double-strand break repair pathway predict glioblastoma survival. J Clin Oncol 28: 2467-2474, 2010.

45. Halle B, Marcusson EG, Aaberg-Jessen C, Jensen SS, Meyer M, Schulz MK, Andersen C and Kristensen BW: Convectionenhanced delivery of an anti-miR is well-tolerated, preserves anti-miR stability and causes efficient target de-repression: A proof of concept. J Neurooncol 126: 47-45, 2015.

46. Stupp R, van den Bent MJ and Hegi ME: Optimal role of temozolomide in the treatment of malignant gliomas. Curr Neurol Neurosci Rep 5: 198-206, 2005.

47. Gilbert MR, Wang M, Aldape KD, Stupp R, Hegi ME, Jaeckle KA, Armstrong TS, Wefel JS, Won M, Blumenthal DT, et al: Dose-dense temozolomide for newly diagnosed glioblastoma: A randomized phase III clinical trial. J Clin Oncol 31: 4085-4091, 2013.

48. Lee J, Ha S, Jung CK and Lee HH: High-mobility-group A2 overexpression provokes a poor prognosis of gastric cancer through the epithelial-mesenchymal transition. Int J Oncol 46: 2431-2438, 2015 